\title{
Predictors of Hypoxemia in children (2-60 months) with lower respiratory tract infection
}

\author{
Malik $\mathbf{S}^{1}$, Gohiya $\mathbf{P}^{2}$, Sisodia $\mathbf{P}^{3}$, Dave $\mathbf{L}^{4}$ \\ ${ }^{1}$ Dr Shikha Malik, Associate Professor, Department of Pediatrics, Gandhi Medical College Bhopal, ${ }^{2}$ Dr Poorva Gohiya, \\ Assistant Professor, Department of Pediatrics, Gandhi Medical College Bhopal, ${ }^{3}$ Dr Pragati Sisodia, Senior Resident \\ Ajmer, Medical College, Ajmer, Rajasthan, ${ }^{4}$ Dr Lokendra Dave, Professor, Department of Chest Medicine, Gandhi \\ Medical College, Bhopal, MP, India
}

Address for Correspondence: Dr Poorva Gohiya, Assistant Professor, Department of Pediatrics, Gandhi Medical College Bhopal gohiyapoorva@gmail.com

\begin{abstract}
Introduction: Acute lower respiratory tract infection specifically pneumonia, account for considerable number of deaths in under 5 children in our country. Hypoxemia is a dangerous sign which needs to be promptly treated. We have taken up this study in order to point out clinical predictors of hypoxemia so that they can be used at peripheral levels where pulse oxymetry the gold standard for measurement of percent oxygen saturation is unavailable. Materials and Methods: The study was conducted in the pediatric intensive care unit of a medical college over a period of one year. This is a prospective cross sectional study. Children in the age group of 2-60 months were included in the study as per the inclusion criteria. Oxygen saturation of $<95 \%$ was taken as cut off for hypoxemia. Results: 150 children were studied out of which $35.3 \%$ had hypoxemia. Breathlessness, fever, irritability, inability to drink/breast feed, unusual sleepiness, convulsions were the presenting symptoms, out of these fever was present in $84 \%$ of children. The most frequent clinical sign was tachypnea (92\%), followed by nasal flaring, chest indrawing and crepitations. There were 6 deaths, which were in the hypoxemic group, and no deaths were in the non-hypoxemic group. Conclusion: No single sign is a good predictor of hypoxemia but a combination of signs when used can act as a surrogate for pulse oxymeter. These signs with high positive predictive value can be easily taught to primary health care workers in the peripheral health centers where pulse oxymeters are not available.
\end{abstract}

Key words: Pulse Oxymeter, Fast Breathing, Grunt, Impaired Consciousness, Positive Predictive Value

\section{Introduction}

Pneumonia accounts for $13 \%$ of deaths in children aged 1-59 months worldwide. The under five mortality of India is 42 per 1000 live births which needs to reduced by 2020 to meet the MDG No.4 [1]. Pneumonia and Diarrheal diseases are the two major causes of mortality in 1-59 months old children [2]. Hypoxemia in pneumonia is an ominous sign, which is picked up with fair accuracy by pulse oxymeter in emergency settings [3,4]. India being a resource limited country, the availability of pulse oxymeter in the remote of areas is a difficult task. Therefore the health care workers rely on clinical features so as to decide which child will require oxygen therapy,

Manuscript received: $26^{\text {th }}$ Nov 2015

Reviewed: $4^{\text {th }}$ Dec 2015

Author Corrected: $14^{\text {th }}$ Dec 2015

Accepted for Publication: $24^{\text {th }}$ Dec 2015 which itself is not freely available and thus a need for referral .We have taken up this study to ascertain the clinical predictors of hypoxemia in 2-60months old children with acute Lower Respiratory tract Infections (LRTIs) so that they can be used as a substitute for pulse oxymetry in resource limited settings.

\section{Material and Methods}

Study Design: Prospective cross sectional study.

Study Period and Place: One Year. PICU Department of Pediatrics of a teaching hospital.

Subjects: Children between 2-60months admitted with acute( $<14$ days) of symptoms of LRTI. A pretested proforma was used to record data of patients which 
was made as per FIMNCI guidelines with emphasis on respiratory system examination.

\section{Inclusion Criteria:}

(1) Children age 2-60 months.

(2) Symptoms of Lower respiratory tract infection for $<14$ days.

\section{Exclusion criteria:}

(1) Children with Congenital Heart Disease.

(2) Children with Asthma and other chronic respiratory disorders.

(3) Children who were referred after cardio pulmonary resuscitation.
(4) Parental consent for inclusion in the study could not be obtained.

Detailed history with respect to respiratory symptoms and other details were obtained preferably from mother. A thorough clinical examination was done by the resident posted in PICU, which was supervised by consultant. Pulse oxymeter used, was LOTUS 500 with an infant probe which was attached to right finger or toe as per comfort of child and reading was recorded after stable pulse formation was seen on the monitor. Investigations done were arterial blood gas analysis, chest $\mathrm{x}$ ray and complete blood count.

Statistical Analysis: The data was analyzed using IBM SPSS 18.

\section{Results}

We enrolled 150 children in the age group 2-60 months who fulfilled the inclusion criteria in the study.111 children were in the age group 2-12 months [table1] with almost equal male female distribution in this age group. Breathlessness, fever, irritability inability to drink/breast feed, unusual sleepiness, convulsions were the presenting symptoms. Fever was present in $84 \%$ of children and breathlessness in $60 \%$. Convulsions were present in only $2.7 \%$ of the subjects. The most frequent clinical sign was tachypnea $(92 \%)$, followed by nasal flaring, chest indrawing and crepitation. Fifty eight percent (58\%) patients had blood hemoglobin more than $10 \mathrm{gm} \%$ and other patients had <10 gm\%. X-ray chest findings in majority of patients were suggestive of consolidation $(55.3 \%)$ followed by hyperinflation $(26 \%)$.

Table 1: Distribution of age in hypoxemic and non hypoxemic children

\begin{tabular}{|c|c|c|c|}
\hline Age in months & $\mathbf{N}$ & Hypoxemic (\%) & Non Hypoxemic (\%) \\
\hline $2-12$ & 111 & $41(36.9)$ & $70(63.1)$ \\
\hline $13-24$ & 24 & $8(33)$ & $16(67)$ \\
\hline $25-36$ & 5 & $1(20)$ & $4(80)$ \\
\hline $37-48$ & 4 & 0 & $4(100)$ \\
\hline $49-60$ & 6 & $3(50)$ & $3(50)$ \\
\hline Total & $\mathbf{1 5 0}$ & $\mathbf{5 3}$ & $\mathbf{9 7}$ \\
\hline
\end{tabular}

\section{( $p$ value 0.636 )}

$64.7 \%$ patients had oxygen saturation of $95 \%-100 \%$ thus total prevalence of hypoxemia was found to be $35.3 \% .30 \%$ of the children had very severe pneumonia. $82.7 \%$ patients were discharged, $12.7 \%$ patients left against medical advice. There were 6 deaths, which were in the hypoxemic group, and no deaths were in the non-hypoxemic group [Table3].

\section{Discussion}

Hypoxemia is an ominous sign in an already critical child having lower respiratory tract infection. All efforts should be directed towards detecting and managing it on a priority basis [5, 6]. Pulse oxymeter is a portable and a reliable instrument to diagnose and monitor saturation of oxygen in blood [7, 8]. Even though it is easy to use its not freely available in the primary health centers of different parts of our country. Even in the tertiary centers as the burden of disease is so high not every sick child can be continuously monitored using pulse oxymeter. Therefore clinical signs and symptoms can act as surrogate markers for exact measurement of hypoxemia when pulse oxymeter is unavailable. Inthepresent study 150 children in the age group $2-60$ months were studied to pick up the predictors of hypoxemia. The prevalence of hypoxemia $\left(\mathrm{SpO}_{2}<95 \%\right)$ was $35.3 \%$ in our study which is higher than found in studies done by Singhi et al $(11.9 \%)$ Lodha et al $(25.7 \%)$ and Supartha et al(17.5\%)[9,10,11].This difference may be due to the different cut off percentage of saturation of oxygenused in the studies and also the settings where the studies were done. 
Inability to drink, unusual sleepiness and convulsions were significantly associated with hypoxemia. Out of these the two best clinical predictor of hypoxemia were inability to drink (sensitivity 77\%, specificity 81\%,PPV 72\%, NPV 87\%) and unusual sleepiness (sensitivity 62\%,specificity 97\%, PPV 91.6\%, NPV 82.4\%). Parents of any of the child in the study did not report bluish discoloration of skin or cyanosis. In study done by Singhi S et al[9] inability to drink was the most specific indicator of hypoxemia with $47.6 \%$ PPV and 92\% NPV similarly in the study done by Supartha M et al [11] inability to drink and unconsciousness were important predictors of hypoxemia. Among various signs cyanosis, fast breathing, chest indrawing, nasal flaring, head nodding, grunting, crepitations and altered consciousness were significantly associated with hypoxemia and in contrast stridor and wheeze was not significantly associated with hypoxemia in our study.

Table 2: Distribution of clinical symptoms and clinical signs in hypoxemic and non-hypoxemic groups

\begin{tabular}{|c|c|c|c|c|c|c|c|c|}
\hline Parameter & $\begin{array}{c}\text { Children } \\
\text { with signs } \\
(\%)\end{array}$ & $\begin{array}{c}\text { Hypoxemic } \\
\text { Children } \\
(n=53)\end{array}$ & $\begin{array}{c}\text { Non } \\
\text { Hypoxemic } \\
\text { Children } \\
(n=97)\end{array}$ & $\begin{array}{l}\text { Sensiti } \\
\text { vity } \\
(\%)\end{array}$ & $\begin{array}{l}\text { Specifi } \\
\text { city } \\
(\%)\end{array}$ & PPV & NPV & P value \\
\hline $\begin{array}{l}\text { Reported fast } \\
\text { breathng }\end{array}$ & $90(60)$ & $39(73 \%)$ & $51(52 \%)$ & 74 & 47 & 43.3 & 76.6 & 0.012 \\
\hline Fever & $126(84)$ & $47(88.6 \%)$ & $79(81.4 \%)$ & 89 & 19 & 37.3 & 75 & 0.251 \\
\hline Irritability & $78(52)$ & $25(47.1 \%)$ & $53(54.6 \%)$ & 47 & 45 & 32 & 61.1 & 0.385 \\
\hline $\begin{array}{l}\text { Inability to } \\
\text { drink }\end{array}$ & $57(38)$ & $41(77.3 \%)$ & $16(16.49 \%)$ & 77 & 77.3 & 71.9 & 87 & 0.000 \\
\hline $\begin{array}{l}\text { Unusual } \\
\text { sleepiness }\end{array}$ & $36(24)$ & $33(62.2 \%)$ & $3(3 \%)$ & 62 & 97 & 91.6 & 82.4 & 0.000 \\
\hline Convulsions & $4(2.7)$ & $4(7.5 \%)$ & 0 & 8 & 100 & 100 & 66.4 & 0.006 \\
\hline Cyanosis & $7(4.6)$ & $7(13.2 \%)$ & 0 & 13 & 100 & 100 & 67.83 & 0.000 \\
\hline Fast breathing & 139(92) & $53(100 \%)$ & $86(88.6)$ & 100 & 11 & 38.1 & 100 & 0.011 \\
\hline Nasal flaring & $122(81.3)$ & $49(92.4)$ & $73(75.25)$ & 92 & 25 & 40 & 85 & 0.009 \\
\hline $\begin{array}{l}\text { Chest } \\
\text { indrawing }\end{array}$ & $73(48.6)$ & $46(86.79)$ & $27(27.80$ & 87 & 72 & 63.1 & 90.9 & 0.000001 \\
\hline Head nodding & $20(13.3)$ & $20(37.7)$ & 0 & 38 & 100 & 100 & 74.6 & 0.000001 \\
\hline Grunting & $7(4.6)$ & $7(13.2)$ & 0 & 13 & 100 & 100 & 67.8 & 0.001 \\
\hline Stridor & $6(4)$ & $4(7.5)$ & $2(2.060$ & 7.5 & 97.93 & 66.6 & 68.05 & 0.103 \\
\hline Wheeze & $59(39.3)$ & $20(37.7)$ & $39(400$ & 38 & 60 & 33.9 & 63.7 & 0.769 \\
\hline Crepitations & $92(61.3 \%)$ & $39(73.5)$ & $53(54.6)$ & 74 & 45 & 42.4 & 75.86 & 0.023 \\
\hline $\begin{array}{l}\text { Altered } \\
\text { consciousness }\end{array}$ & $46(30.6)$ & $39(73.5)$ & $7(7.2)$ & 74 & 93 & 84.7 & 86.53 & 0.00001 \\
\hline
\end{tabular}

Table- 3: Distribution of investigations in hypoxemic and non hypoxemic group

\begin{tabular}{|c|c|c|c|c|c|c|}
\hline \multirow[t]{2}{*}{ Investigations } & \multirow[t]{2}{*}{ Results } & \multicolumn{2}{|c|}{ Hypoxemia } & \multicolumn{2}{|c|}{ Non Hypoxemia } & \multirow[t]{2}{*}{$P$ value } \\
\hline & & $\mathbf{N}$ & $\%$ & $\mathbf{N}$ & $\%$ & \\
\hline Hemoglobin & $\mathrm{Hb}<10 \mathrm{gm} \%$ & 33 & 62.26 & 30 & 30.9 & $<0.001$ \\
\hline \multirow[t]{5}{*}{$\mathrm{X}$-ray findings } & Consolidation & 34 & 68 & 49 & 50 & \multirow{5}{*}{0.265} \\
\hline & Hyperinflation & 9 & 18 & 30 & 30.9 & \\
\hline & Normal & 4 & 8 & 15 & 15.46 & \\
\hline & Collapse & 2 & 4 & 3 & 3 & \\
\hline & Pleural effusion & 1 & 2 & 0 & 0 & \\
\hline \multirow[t]{2}{*}{ ABGA } & $\mathrm{PH}<7.35$ & 37 & 78.7 & 13 & 17.5 & $<0.001$ \\
\hline & $\mathrm{Po}_{2}<80$ & $31 / 47$ & 65.9 & 3 & 3.6 & 0.005 \\
\hline
\end{tabular}

Fast breathing or tachypnea was significantly associated with hypoxemia in our study though with low positive predictive value which is in accordance with studies done by Martin W and Supartha et al. Chest indrawing showed 87\% sensitivity and 63\% PPV [Table2] which is similar to studies done by Singhi S and Supartha M et al. 
Though studies by Martin W and Usen S et al did not find chest indrawing a useful predictor. Head nodding had $100 \%$ positive predictive value for hypoxemia [table2]. Supartha $M$ et al and Usen S [12] et al also find head nodding as a useful predictor for hypoxemia. Grunting is a considered a dangerous sign in a child with respiratory distress as it suggests hypoxemia. In our study we found that $38 \%$ of the patients will be missed if we consider grunting as a single predictor for hypoxemia as it has a negative predictive value of $67.8 \%$.

Usen $\mathrm{S}$ et al found grunting as an independently significant predictor of hypoxemia, in their study which focused on $\mathrm{H}$. influenzae b pneumonia. Cyanosis was found to be a good independent clinical predictor of hypoxemia with, 100\% specificity, $100 \%$ PPV and 67.83\%NPV.It is often difficult to detect due to dark complexion although when present, it is highly specific for hypoxemia. Different researchers have found similar results in their studies [12,13]. Supartha M et al, in their study found cyanosis as the best clinical predictor of hypoxemia [11].

We found altered level of consciousness $74 \%$ sensitive, 93\% specific, and had $84.7 \%$ PPV and $86.5 \% \%$ NPV. It was very useful sign and was strongly associated with hypoxemia. In a study done by Martin W combination of quality of cry, head nodding and cyanosis was $59 \%$ sensitive and $93 \%$ specific in predicting thepresence of hypoxemia. In study done at Gambia [12] no spontaneous movement during examination was specific but relatively insensitive sign. It was independent and significant predictor of hypoxemia. Supartha $\mathrm{M}$ et al in their study concluded un- consciousness as one of the important single predictor of hypoxemia [11].

According to our study presence of hypoxemia is predictive of short term mortality, indicating that the detection and treatment of hypoxemia may be a crucial part of clinical management of these severely ill children in hospital. Conversely absence of hypoxemia predicts a low risk of death, even in the presence of radiological pneumonia.

Our observations correlated well with the study by Onyango et al [14]in which short term mortality was 3-4 times greater in hypoxemic children.

The clear association of hypoxemia with mortality suggests that the detection and effective treatment of hypoxemia with supplemental oxygen are important aspects in the management of these patients. To promote rational use of supplemental oxygen in children with respiratory distress, combination of signs with high sensitivity, such as fast breathing, inability to drink, nasal flaring, chest indrawing, altered consciousness may be preferable as an indicator of need for oxygen therapy.

\section{Conclusion}

Our study revealed prevalence of hypoxemia to be $35.3 \%$ and its strong association with early mortality. Thus early detection of hypoxemia and its timely management can decrease deaths due to pneumonia and other acute lower respiratory tract infections and this decrease in turn will reduce the under fivemortality rate.

Combination of signs with high positive predictive value and specificity, which included chest indrawing, head nodding, cyanosis, fast breathing, impaired consciousness can be utilized in settings where pulse oxymeter are not available.

These clinical signs are easy to assess and can be taught to health care workers taking care of sick children at primary health centers. This will help in early management of critical children who require oxygen and also their prompt referral to a higher center if oxygen is not available. Significantly high mortality rate was $(11.3 \%)$ was associated with hypoxemic group. Presence of hypoxemia is predictive of short term mortality, indicating that the detection and treatment of hypoxemia may be a crucial part of clinical management of severely ill children in hospital.

\section{References}

1. Infant and Child Mortality in India; levels trends and determinants. National Institute of Medical StastisticsICMR

report.http://unicef.in/Uploads/Publications/Resources/ pub_doc35.pdf

2. Garenne M, Ronsmans C, Campbell H. Themagnitude of mortality from acuterespiratoryinfections in children under 5 years indeveloping countries. World Health Statistics Quarterly 1992; 45: 180-191. 
3. Bryce J, Boschi Pinto C, Shibuya K, Black RE. WHO estimate of the causes of death in children.Lancet. 2005.1;365(9465):1147-1152.PMID: 15794969

4. Margolis PA, FerkolTW,MarsocciS,Super DM, Keyes LL, Mcnutt R, Harelli FE Jr .Accuracy of clinical examination in detecting hypoxemia in infants with respiratory illness. J Pediatr, 1994; 124(4): 552-560.

5. WHO pocket book of hospital care for children: Guidelines for the management of common illness with limited resources; 2005.

6. Leon C, Ricardo A, Stephen M, Mary Fran H. Pediatric Advanced Life support $7^{\text {th }}$ edition.

7. F-MNCIFacility based integrated management of neonatal and childhood illness. Pg no 111-113.

8. Park K. Park's Textbook of Preventive and Social medicine, $21^{\text {st }}$ Edition Pg 156.

9. Singhi S, Deep A, KaurH. Prevalence \& predictors of hypoxemia in acute respiratory infections presenting topediatric emergency department. Indian J Crit Care $\begin{array}{lll}\text { Med } & 2003 ; 7 & \text { (2): }\end{array}$ http://www.ijccm.org/text.asp?2003/7/2/118/5739
10. RakeshLodha, Prateek Singh Bhaduria ,AnoopVerghese Kuttikat, Madhavi Puranik, SaurabhGupta,Pandey R M , Kabra S.K. Can clinical symptoms and signs accurately predict hypoxemia in children with acute lowerrespiratory tractinfections? Indian Pediatrics 2004;41(2):129-135.

11. Made Supartha, PutuSiadiPurniti, RoniNaning, IdaBagusSubananda..Clinical predictors of hypoxemia in 1-5 year old children with pneumonia. PaediatricaIndonesiana. $\quad 2010 ; 50 \quad$ (6): 355-360. http://paediatricaindonesiana.org/pdffile/50-6-8.pdf

12. Stanley Usen, Martin Weber, Kim Mulholland, ShabbarJaffar, AnslemOparaugo, Charles Omosighu, Richard Adegboda, Greenwood. Clinical predictors of hypoxemia in Gambian children with ALRI ,a prospective cohort study .BMJ. 1999; 318(7176):8691.PMC27680.

13. Martin W Weber, Stanley Usen, Ayo Palmer, ShabbarJaffar, Kim Mulholland.Gambia. Predictors of hypoxemia in hospital admission with ALRI in a developing country. Archives Of Disease In Childhood1997;76(4) : 310-314.PMC1717166.

14. Onyago F E, Steinhoff M C, Wafula E M,WariuaS,Musia J, Kitonyi J. Hypoxemia in young Kenyan children with acute lower respiratory tract infection. BMJ 1993; 306 :612-15. PMC 1676956.

\section{How to cite this article?}

Malik S, Gohiya P, Sisodia P, Dave L. Predictors of Hypoxemia in children (2-60 months) with lower respiratory tract infection. Pediatr Rev: Int J Pediatr Res 2015;2(4):138-142.doi:10.17511/ijpr.2015.i04.19 